\title{
Institutional and population based analyses on misdiagnosis of appendicitis in Khulna, Bangladesh
}

\author{
BK Basu ${ }^{1 凶}$, MM Rashid ${ }^{2}$, MS Laskar ${ }^{3}$, MT Islam ${ }^{4}$
}

\begin{abstract}
The aim of the present study was to identify factors associated with misdiagnosis of appendicitis to propose solutions to decrease the misdiagnosis rate of appendicitis. The study conducted an institutional and a population based analyses on misdiagnosis of appendicitis conducted in Khulna district, Bangladesh. The study dealt with 2 groups of patients. Group 1 consisted of the patients treated in Gazi Medical College Hospital (GMCH), Khulna either in out-patient department (OPD) within the last 3 years (from 2014 to 2016), treating doctors suggested appendicectomy and in indoor-patient department (IPD) within the last 5 years (from 2012 to 2016), the diagnosis was done either during operation or admitted as postoperative complications. Patients for Group 2 were selected purposively from the patients who were from different villages of Rupsha and Fakirhat Upazila or from Khulna city previously underwent appendicectomy within the last 5 years (from 2012 to 2016) in different hospitals other than $\mathrm{GMCH}$, Khulna and previous symptoms were still existed. The study revealed that the majority of the patients were female (OPD $81.5 \%$, IPD $68.8 \%$ in Group 1 and $83.2 \%$ in Group 2). The misdiagnosis rate of appendicitis for the patients attended GMCH OPD and GMCH IPD was $23.0 \%$ and $8.9 \%$, respectfully. The overall misdiagnosis rate of appendicitis for the patients attended $\mathrm{GMCH}$ was $14.0 \%$. In case of the patients attended GMCH OPD, most of them had UTI and chronic cystitis (45.5\%). In case of the patients attended GMCH IPD, most of them had non-inflamed appendix (84.4\%). The misdiagnosis rate of appendicitis for the patients in Group 2 was $23.2 \%$. Some factors were identified and bearing in mind the factors, all the concerned should be more careful and conscious while making the diagnosis of appendicitis to avoid misdiagnosis and patients' suffering.
\end{abstract}

Key words: Misdiagnosis, appendicitis, factors, institutional and population based analyses.

\section{Introduction}

Appendicitis is the inflammation of the vermiform of appendix, usually which requires its surgical removal (appendicectomy/ appendectomy) for the treatment of the disease due to its life threatening complications. Appendicitis may present many vague symptoms including abdominal pain (beginning near the belly bottom and spreading to the lower right abdomen), anorexia, nausea, vomiting, constipation, diarrhea, inability to pass gas, abdominal swelling, fever, downward pull like a need for bowel movement, etc.

Appendicitis is the most frequent acute abdomen disease with the lifetime incidence

1. BK Basu, Associate Professor of Surgery, Gazi Medical College Hospital, Khulna. Email: bangakamalb@yahoo.com

2. MM Rashid, Assistant Professor of Anaesthesiology, Gazi Medical College Hospital, Khulna

3. MS Laskar, Professor of Community Medicine, Gazi Medical College, Khulna

4. MT Islam, Assistant Professor of Burn and Plastic Surgery, Khulna Medical College Hospital, Khulna 
of approximately $7 \% .^{1}$ Appendicectomy may be performed as an open (laparotomy) operation or laparoscopically (minimally invasive surgery) and it is the most frequently performed surgical procedure. The adverse outcomes of presumed appendicitis are: perforation, often occurring in the prehospital setting, and misdiagnosis, resulting in removal of a normal appendix. Though the mortality rate is 2 to $4 \%$ till now due to this disease and its complications, the rate of misdiagnosis in patients may be upto $40 \%$. $^{2-7}$ Despite technologic advances, the diagnosis of appendicitis is still based primarily on the patient's history and the physical examination. ${ }^{8}$ This relatively high rate of unnecessary appendicectomy is being challenged while there is dramatic expansion of diagnostic testing options for appendicitis during the last decade. Many investigators have demonstrated that in research environments, advanced diagnostic testing using computed tomography (CT), ultrasonography (USG), and laparoscopy decreases the frequency of misdiagnosis. ${ }^{9-14}$ However, some other investigators contrary to expectation have reported that the frequency of misdiagnosis leading to unnecessary appendicectomy has not changed with the introduction of CT, USG, and laparoscopy, nor has the frequency of perforation decreased. ${ }^{15,16}$ They also have suggested that on a population level, diagnosis of appendicitis has not improved with the availability of advanced diagnostic testing.

In the context of our country, the factors leading to misdiagnosis are less understood. Therefore, the aim of our study was to identify factors associated with misdiagnosis of appendicitis to propose solutions to decrease the misdiagnosis rate of appendicitis.

\section{Materials and Method}

An institutional and a population based analyses on misdiagnosis of appendicitis was conducted in Khulna district, Bangladesh.

There were two groups of patients in this study. Group 1 consisted of the patients treated in Gazi Medical College Hospital $(\mathrm{GMCH})$, Khulna either in out-patient depart- ment (OPD) within the last 3 years (from 2014 to 2016), treating doctors suggested appendicectomy and in indoor-patient department (IPD) within the last 5 years (from 2012 to 2016), the diagnosis was done either during operation or admitted as postoperative complications. Patients for Group 2 were selected purposively from the patients who were from different villages of Rupsha and Fakirhat Upazila or from Khulna city previously underwent appendicectomy within the last 5 years (from 2012 to 2016) in different hospitals other than $\mathrm{GMCH}$, Khulna and previous symptoms were still existed.

Data were collected, compiled and entered in spreadsheet (Microsoft Excel) and analyzed using appropriate statistical tools. Results were reported as percentage (\%).

\section{Results}

The number of patients (Group 1) attended $\mathrm{GMCH}$, Khulna, OPD within the last 3 years (from 2014 to 2016) and IPD within the last 5 years (from 2012 to 2016) was 621 and 1081, respectfully. The number of patients (Group 2) attended elsewhere other than $\mathrm{GMCH}$, Khulna, previously underwent appendicectomy within the last 5 years (from 2012 to 2016) but previous symptoms were still existed was 656 (Rupsha- 296, Fakirhat328 and others- 32 ).

Table 1 shows the ender distribution of the patients in Group 1 and Group 2. Majority of the patients were female (OPD 81.5\%, IPD $68.8 \%$ in Group 1 and $83.2 \%$ in Group 2).

Table 2 shows the distribution of the patients in Group 1 with diagnosis of appendicitis. The misdiagnosis rate of appendicitis for the patients attended GMCH OPD and $\mathrm{GMCH}$ IPD was $23.0 \%$ and $8.9 \%$, respectfully. The overall misdiagnosis rate of appendicitis for the patients attended $\mathrm{GMCH}$ was $14.0 \%$.

Fig. 1 presents the updated disease profiles of the patients misdiagnosed for appendicitis in Group 1 who attended GMCH OPD. The most of the patients had UTI and chronic cystitis (45.5\%). Fig. 2 shows the updated disease profiles of the patients misdiagnosed 
Table 1. Gender distribution of the patients in Group 1 and Group 2

\begin{tabular}{|c|c|c|c|c|c|c|c|c|}
\hline & \multicolumn{6}{|c|}{$\begin{array}{l}\text { Patients attended in Gazi Medical College } \\
\text { Hospital (Group 1) }\end{array}$} & \multirow{2}{*}{\multicolumn{2}{|c|}{$\begin{array}{l}\text { Patients } \\
\text { attended } \\
\text { elsewhere } \\
\text { (Group 2) }\end{array}$}} \\
\hline & \multicolumn{2}{|c|}{ OPD patients } & \multicolumn{2}{|c|}{ IPD patients } & \multicolumn{2}{|c|}{$\begin{array}{c}\text { Total } \\
\text { patients }\end{array}$} & & \\
\hline & $\mathrm{n}$ & $\%$ & $\mathrm{n}$ & $\%$ & $\mathrm{n}$ & $\%$ & $\mathrm{n}$ & $\%$ \\
\hline Male & 115 & 18.5 & 337 & 31.2 & 452 & 26.6 & 110 & 16.8 \\
\hline Female & 506 & 81.5 & 744 & 68.8 & 1250 & 73.4 & 546 & 83.2 \\
\hline Total & 621 & 100.0 & 1081 & 100.0 & 1702 & 100.0 & 656 & 100.0 \\
\hline
\end{tabular}

Table 2. Distribution of the patients in Group 1 with diagnosis of appendicitis

\begin{tabular}{lrrrrrrrr}
\hline & \multicolumn{2}{c}{ OPD patients } & & \multicolumn{2}{c}{ IPD patients } & & \multicolumn{2}{c}{ Total patients } \\
\cline { 2 - 3 } & $\mathrm{n}$ & $\%$ & & $\mathrm{n}$ & $\%$ & & $\mathrm{n}$ & $\%$ \\
\hline With correct diagnosis & 478 & 77.0 & & 985 & 91.1 & & 1463 & 86.0 \\
With misdiagnosis & 143 & 23.0 & & 96 & 8.9 & & 239 & 14.0 \\
\hline Total & 621 & 100.0 & & 1081 & 100.0 & & 1702 & 100.0 \\
\hline
\end{tabular}

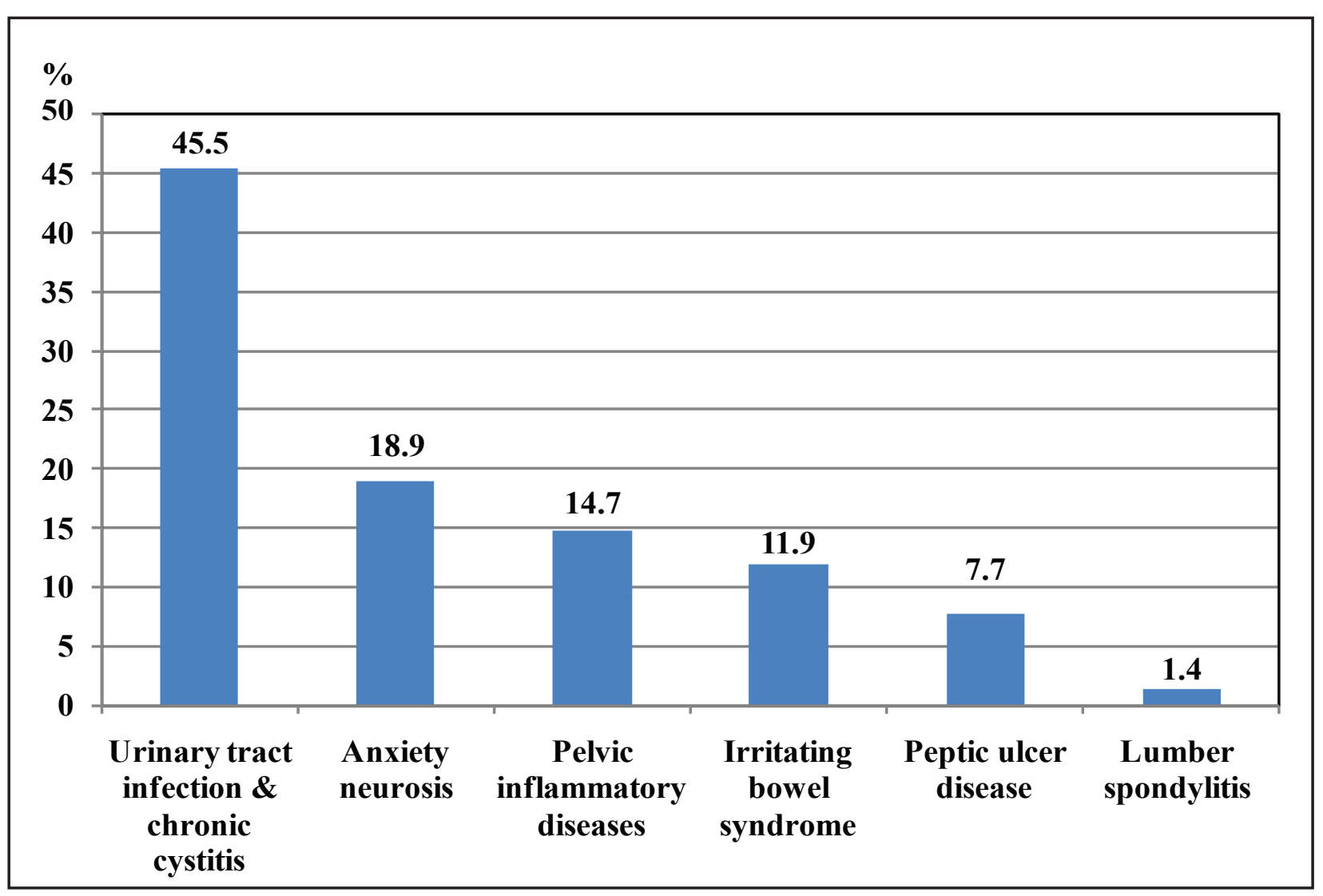

Fig. 1. Updated disease profiles of the patients misdiagnosed for appendicitis in Group 1, attended OPD. 


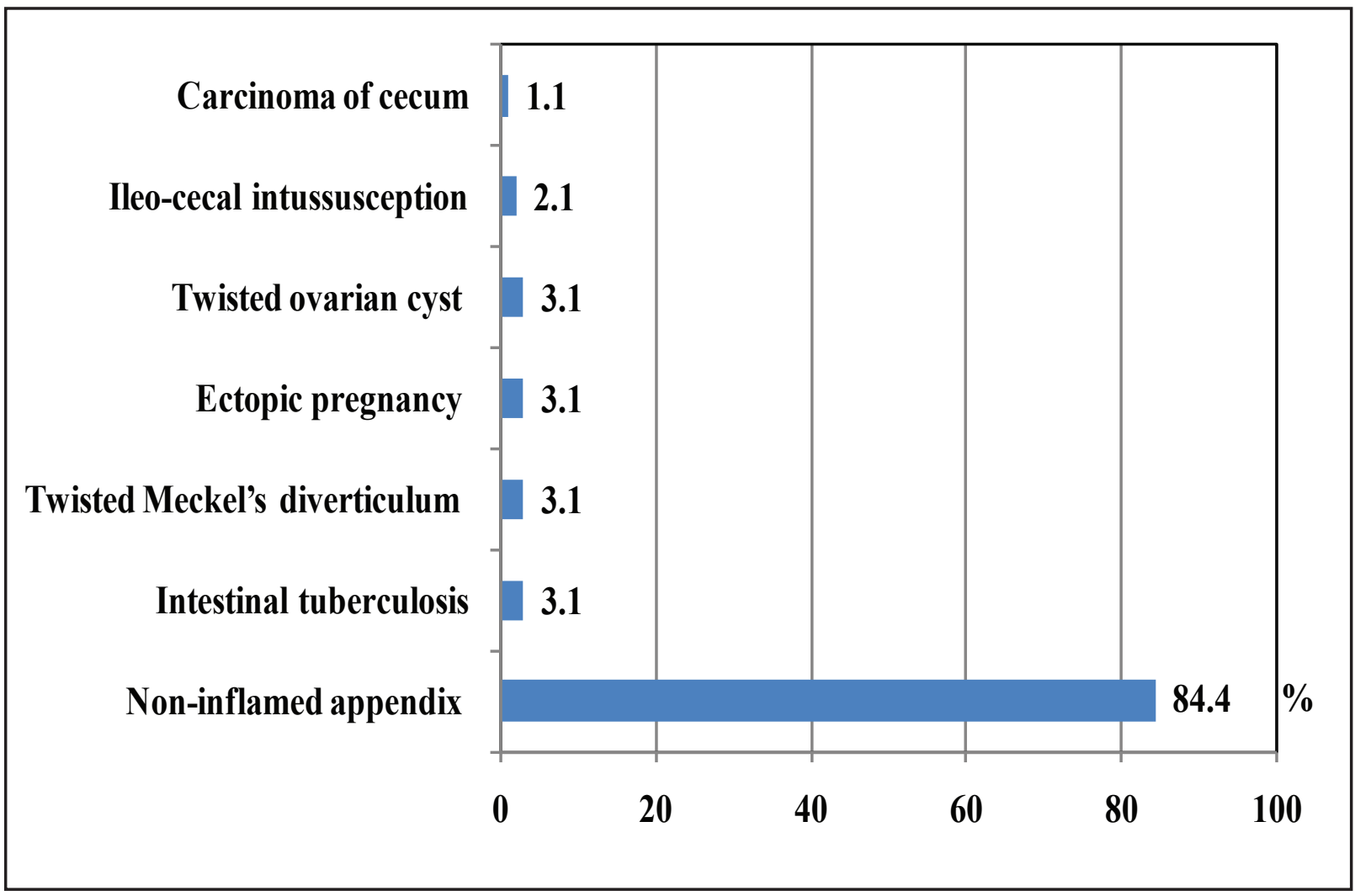

Fig. 2. Updated disease profiles of the patients misdiagnosed for appendicitis in Group 1, attended IPD.

Table 3. Distribution of the patients in Group 2 with diagnosis of appendicitis

\begin{tabular}{lrr}
\hline & \multicolumn{2}{c}{ Patients in Group 2 } \\
\cline { 2 - 3 } & $\mathrm{n}$ & $\%$ \\
\hline With correct diagnosis & 503 & 76.7 \\
With misdiagnosis & 153 & 23.3 \\
\hline Total & 656 & 100.0 \\
\hline
\end{tabular}

for appendicitis in Group 1 who attended IPD. The most of the patients had non-inflamed appendix (84.4\%).

Table 3 presents the distribution of the patients in Group 2 with diagnosis of appendicitis. The misdiagnosis rate of appendicitis for the patients in Group 2 was $23.2 \%$.

\section{Discussion}

The present study of institutional and population based analyses on misdiagnosis of appendicitis conducted in Khulna district, Bangladesh revealed that the majority of the patients were female (OPD $81.5 \%$, IPD $68.8 \%$ in Group 1 and $83.2 \%$ in Group 2). The misdiagnosis rate of appendicitis for the patients attended $\mathrm{GMCH}$ OPD and $\mathrm{GMCH}$ IPD was $23.0 \%$ and $8.9 \%$, respectfully. The overall misdiagnosis rate of appendicitis for the patients attended $\mathrm{GMCH}$ was $14.0 \%$. The misdiagnosis rate of appendicitis for the patients in Group 2 was $23.2 \%$. A male preponderance exists, with a male to female ratio of 1.1 to $3: 1$; the overall lifetime risk is $9 \%$ for males and $6 \%$ for females. A difference in diagnostic error rate ranges from $12 \%$ to $23 \%$ for men and $24 \%$ to $42 \%$ for women. ${ }^{17-20}$ Difficulties of diagnosis of atypical cases result from variation of the anatomical position of the appendix, appendicitis occurring at extremes of age and in females during child bearing age. ${ }^{21}$

In case of the patients attended GMCH OPD, most of them had UTI and chronic cystitis $(45.5 \%)$. In case of the patients attended 
GMCH IPD, most of them had non-inflamed appendix $(84.4 \%)$. The clinical diagnosis of acute appendicitis relies upon a detailed history and thorough physical examination and the differential diagnosis is that of the acute abdomen as it can mimic the presentation of most abdominal emergencies. ${ }^{22}$ Considering differential diagnosis, both obstetrical and gynecological conditions can present with abdominal pain and mimic appendicitis. Non-obstetrical/ non-gynecological conditions include gastroenteritis, urinary tract infections, pyelonephritis, cholecystitis, cholelithiasis, pancreatitis, nephrolithiasis, hernia, bowel obstruction, carcinoma of the large bowel, mesenteric adenitis, and rectus hematoma, pulmonary embolism, rightlower-lobe pneumonia, and sickle cell disease. Gynecologic and obstetric conditions include ovarian cyst, adnexal torsion, salpingitis, abruptio placenta, chorioamnionitis, degenerative fibroid, ectopic pregnancy, preeclampsia, round ligament syndrome, and preterm labour. ${ }^{23,24}$

Among the causes which leads doctors to misdiagnosis may be a) low socioeconomical status of the patients, b) poor investigation facilities, c) expensive investigation facilities, d) misinformation to the patients and their attendants, e) malpractice by doctors, etc. No single evaluation can substitute for the diagnostic accuracy of the experienced physician. The decision to obtain USG or CT scan studies depends on institutional preference and the available user expertise, although patient age, sex, and body habitus are important influencing factors. Physicians have a duty to use the requisite care and skills of a competent physician who practices in the same medical community; in other words, they are held to a certain minimum standard of care in performing the procedure. Their staff is also held to similar standards, and a physician along with nurses and anyone else involved in a medical procedure or in the care of a patient can be held liable in a medical malpractice action. Hospitals can also be held responsible if they hired the surgeon and staff that committed a preventable medical error. Therefore, bearing in mind the factors, all the concerned should be more careful and conscious while making the diagnosis of appendicitis to avoid misdiagnosis and patients' suffering.

\section{References}

1. Kryzauskas M, Danys D, Poskus T, et al. Is acute appendicitis still misdiagnosed? Open Med 2016;11:231-6.

2. Ruffolo C, Fiorot A, Pagura G, et al. Acute appendicitis: what is the gold standard of treatment? World J Gastroenterol 2013;19(47):8799-807.

3. Zoarets I, Poluksht N, Halevy A. Does selective use of computed tomography scan reduce the rate of "white" (negative) appendectomy. Isr Med Assoc J 2014;16:335-7.

4. Pittman-Waller VA, Myers JG, Stewart RM, et al. Appendicitis: why so complicated? Analysis of 5755 consecutive appendectomies. Am Surg 2000;66:548-54.

5. Styrud J, Eriksson S, Segelman J, Granstrom L. Diagnostic accuracy in 2351 patients undergoing appendicectomy for suspected acute appendicitis: a retrospective study 1986-1993. Dig Surg 1999;16:39-44.

6. Wong SW, Haxhimolla H, Grieve DA, Fisher R, Keogh G. Insurance and the risk of ruptured appendix in the adult. Aust N Z J Surg 1999;69:31-3.

7. Borgstein PJ, Gordijn RV, Eijsbouts QA, Cuesta MA. Acute appendicitis- a clearcut case in men, a guessing game in young women: a prospective study on the role of laparoscopy. Surg Endosc 1997;11:923-7.

8. Hardin DMJr. Acute appendicitis: review and update. Am Fam Physician 1999;60(7):2027-34.

9. Rao PM, Rhea JT, Novelline RA, Mostafavi AA, McCabe CJ. Effect of computed tomography of the appendix on treatment of patients and use of hospital resources. N Engl J Med 1998;338:141-6.

10.Balthazar EJ, Rofsky NM, Zucker R. Appendicitis: the impact of computed tomography imaging on negative appendectomy and perforation rates. Am J Gastroenterol 1998;93:768-71. 
11.Franke C, Bohner $\mathrm{H}$, Yang Q, Ohmann C, Roher HD. Ultrasonography for diagnosis of acute appendicitis: results of a prospective multicenter trial. World $\mathrm{J}$ Surg 1999;23:141-6.

12.Jadallah FA, Abdul-Ghani AA, Tibblin S. Diagnostic laparoscopy reduces unnecessary appendicectomy in fertile women. Eur J Surg 1994;160:41-5.

13. Rao PM, Rhea JT, Rattner DW, Venus LG, Novelline RA. Introduction of appendiceal CT: impact on negative appendectomy and appendiceal perforation rates. Ann Surg 1999;229:344-9.

14.Barrat C, Catheline JM, Rizk N, Champault GG. Does laparoscopy reduce the incidence of unnecessary appendicectomies? Surg Laparosc Endosc 1999;9:27-31.

15.Flum DR, Morris A, Koepsell T, Dellinger EP. Has misdiagnosis of appendicitis decreased over time? A populationbased analysis. JAMA 2001;286(14): 1748-53.

16.Neary W, Dellinger EP, Koepsell T, Morris A. Misdiagnosis of appendicitis continues despite new tools. University of Washington. http://www.washington.edu/news/ 2001/10/09/misdiagnosis-of-appendicitis- continues-despite-new-tools/ (Accessed on April 15, 2017).

17.Graffeo CS, Counselman FL. Appendicitis. Emerg Med Clin N Am 1996;14:653-71.

18.Shelton T, McKinlay R, Schwartz RW. Acute appendicitis. Curr Surg 2003;60:502-5.

19. Hawkins JD, Thirlby RC. The accuracy and role of cross-sectional imaging in the diagnosis of acute appendicitis. Adv Surg 2009;43:13-22.

20. Humes DJ, Simpson J. Acute appendicitis. Br Med J 2006;333:530-4.

21. Mohamed A, Bhat N. Acute appendicitis dilemma of diagnosis and management. Internet J Surg 2009;23(2):1-10.

22. Humes DJ, Simpson J. Clinical presentation of acute appendicitis: clinical signs laboratory findings - clinical scores, Alvarado score and derivative scores. In: Keyzer C, Gevenois PA, editors. Imaging of acute appendicitis in adults and children. Springer-Verlag; 2011.

23.Pastore PA, Sauret J. Appendicitis in pregnancy. J Am Board Fam Med 2006;19:621-6.

24.Birnbaum BA, Wilson SR. Appendicitis at the millennium. Radiology 2000;215:349-52.

\section{Suggestion for citation of the above:}

Basu BK, Rashid MM, Laskar MS, Islam MT. Institutional and population based analyses on misdiagnosis of appendicitis in Khulna, Bangladesh. Mediscope 2017;4(2):29-34. 